\title{
JOURNAL OF APPLIED PROBABILITY VOLUME 47 (2010): INDEX
}

AllaARt, P. A general 'bang-bang' principle for predicting the maximum of a random walk .....

Alodat, M. T., Al-Rawwash, M. and Jebrini, M. A. Duration distribution of the conjunction of

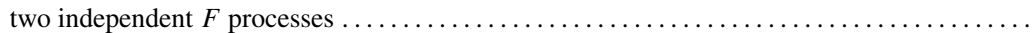

Al-Rawwash, M. see Alodat, M. T.

Ano, K., KaKinuma, H. And Miyoshi, N. Odds theorem with multiple selection chances ........ Aoudia, D. A. AND Marchand, E. On the number of runs for Bernoulli arrays $\ldots \ldots \ldots \ldots \ldots$. Balaji, S., Mahmoud, H. And Tong, Z. Phases in the diffusion of gases via the Ehrenfest urn model Balakrishnan, N. see Navarro, J.

Barbour, A. D. And Pollett, P. K. Total variation approximation for quasi-stationary distributions

Bar-Lev, S. K., Boxma, O. And Letac, G. A characterization related to the equilibrium distribution associated with a polynomial structure

$1093-1104$

367-377

$841-855$

934-946

$1136-1149$

BASRAK, B. Limit theorems for the inductive mean on metric trees $\ldots \ldots \ldots \ldots \ldots \ldots \ldots \ldots \ldots$

Berman, S. M. Probabilistic analysis of the efficacy of periodic testing of employees ...........

BLANCHET, J. AND LIU, J. Efficient importance sampling in ruin problems for multidimensional

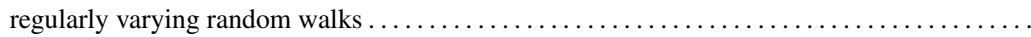

Block, H. W., Langberg, N. A., Savits, T. H. and Wang, J. Continuous mixtures of exponentials and IFR gammas having bathtub-shaped failure rates $\ldots \ldots \ldots \ldots \ldots \ldots \ldots \ldots \ldots \ldots \ldots \ldots$

Boxma, O., Perry, D., Stadje, W. and Zacks, S. The busy period of an M/G/1 queue with customer impatience.

$1174-1190$

$301-322$

899-907

$130-145$

$441-458$

Breuer, L. A quintuple law for Markov additive processes with phase-type jumps

$441-458$

CÁrcamo, J. see de la CAL, J.

Chen, A. see Chen, Y.

Chen, M.-R. And Hsiau, S.-R. Two new models for the two-person red-and-black game........

Chen, Y., Chen, A. And NG, K. W. The strong law of large numbers for extended negatively

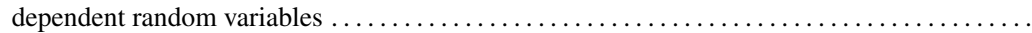

$97-108$

908-922

Cohen, N., Jordan, J. and Voliotis, M. Preferential duplication graphs .................

Coutin, L., Decreusefond, L. And Dhersin, J.-S. A Markov model for the spread of viruses in an open population.

$572-585$

976-996

$146-156$

DALY, F. Stein's method for compound geometric approximation $\ldots \ldots \ldots \ldots \ldots \ldots \ldots \ldots \ldots \ldots \ldots$
D'Auria, B., Ivanovs, J., Kella, O. And MandJes, M. R. H. First passage of a Markov additive

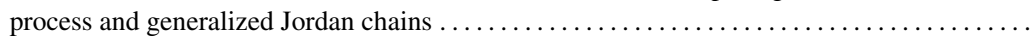

DE LA CAL, J. AND CÁRCAMO, J. Inverse stochastic dominance, majorization, and mean order statistics

Dȩbicki, K., Es-Saghouani, A. And Mandjes, M. Transient asymptotics of Lévy-driven queues .

DeCreusefond, L. see Coutin, L.

DeIJfen, M. Random networks with preferential growth and vertex death $\ldots \ldots \ldots \ldots \ldots \ldots \ldots$

Denuit, M. M. And Mesfioui, M. Generalized increasing convex and directionally convex orders Positive dependence of signals

$1048-1057$

277-292

$109-129$

$1150-1163$

264-276

893-897

Dhersin, J.-S. see Coutin, L.

Di Crescenzo, A. And Martinucci, B. A damped telegraph random process with logistic stationary

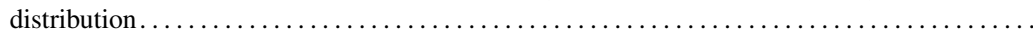

DING, W. see LI, X.

DolinsKy, Y. Shortfall risk approximations for American options in the multidimensional BlackScholes model. 
Dufour, F. And Piunovskiy, A. B. Multiobjective stopping problem for discrete-time Markov

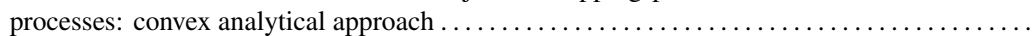

Ekström, E., Lindberg, C., Tysk, J. And Wanntorp, H. Optimal liquidation of a call spread....

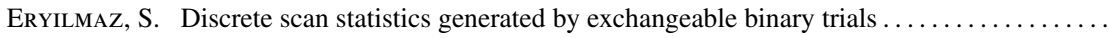

Es-Saghouani, A. see DȩBicki, K.

Fackrell, M., He, Q.-M., TAYlor, P. and Zhang, H. The algebraic degree of phase-type

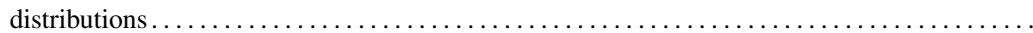

FENG, Q. ANd Mahmoud, H. M. On the variety of shapes on the fringe of a random recursive tree

FIELD, A. J. AND HaRrison, P. G. Busy periods in fluid queues with multiple emptying input states

Finkelstein, M. A note on converging geometric-type processes $\ldots \ldots \ldots \ldots \ldots \ldots \ldots \ldots \ldots$

Fontbona, J., Krell, N. and Martínez, S. Energy efficiency of consecutive fragmentation

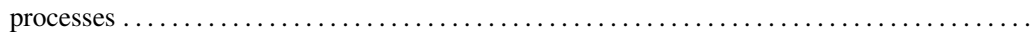

Fralix, B. H. AND Riaño, G. A new look at transient versions of Little's law, and M/G/1 preemptive last-come-first-served queues

947-966

$586-593$

$1084-1092$

$611-629$

$191-200$

$474-497$

601-607

$543-561$

$459-473$

FU, J. C. AND WU, T.-L. Linear and nonlinear boundary crossing probabilities for Brownian motion

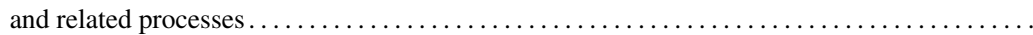

Fuming, L. see ZuOXIANG, P.

GANTI, R. K. AND HaEngGi, M. Limit of the transport capacity of a dense wireless network ......

González, M. Martínez, R. and Slavtchova-Bojkova, M. Stochastic monotonicity and continuity properties of the extinction time of Bellman-Harris branching processes: an

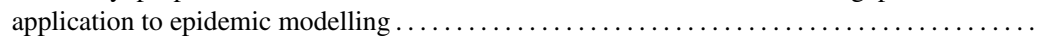

GuPTA, R. C. AND GUPTA, R. D. Random effect bivariate survival models and stochastic comparisons Gupta, R. D. see Gupta, R. C.

Gut, A. Limit theorems for a generalized St Petersburg game $\ldots \ldots \ldots \ldots \ldots \ldots \ldots \ldots \ldots \ldots$

HaEngGi, M. see GANTI, R. K.

Harrison, P. G. see Field, A. J.

He, Q.-M. see FACKRELl, M.

Hernández-Lerma, O. see Mendoza-Pérez, A. F.

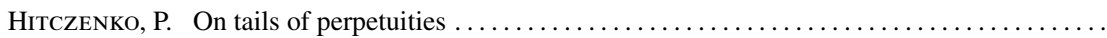

Hsiau, S.-R. see Chen, M.-R.

Hult, H. AND SAmorodnitsky, G. Large deviations for point processes based on stationary

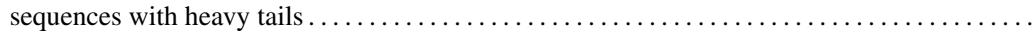

IKSANOv, A. AND MeINERs, M. Exponential rate of almost-sure convergence of intrinsic martingales

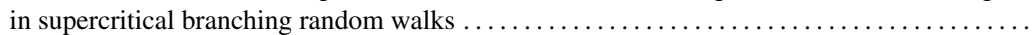

IvANovs, J. Markov-modulated Brownian motion with two reflecting barriers .............. see D'AURIA, B.

JANSON, S., ŁUCZAK, T. AND NoRros, I. Large cliques in a power-law random graph............

Jebrini, M. A. see Alodat, M. T.

JoRdAn, J. see COHEN, N.

KAKINUMA, H. see ANO, K.

KAPLun, A. The continuous-time Ehrenfest process in term structure modelling .............

Karagrigoriou, A. see Vonta, F.

Kella, O. see D'Auria, B.

Khandwawala, M. and Sundaresan, R. Optimal multicommodity flow through the complete

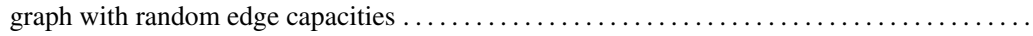

Kondratiev, Y., Kozitsky, Y. And Pasurek, T. Gibbs random fields with unbounded spins on

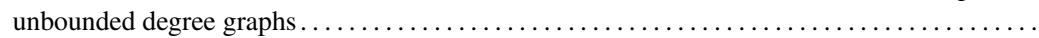

Konstantinides, D. G., NG, K. W. And TAng, Q. The probabilities of absolute ruin in the renewal risk model with constant force of interest . . . . . . . . . . . . . . . . . . . . . . . . . . . . .

Kozitsky, Y. see Kondratiev, Y.

Krell, N. see Fontbona, J.

Kuznetsov, A. Wiener-Hopf factorization for a family of Lévy processes related to theta functions LANGBERG, N. A. see Block, H. W.

Lebensztayn, E., Machado, F. P. and Martinez, M. Z. Nonhomogeneous random walks systems

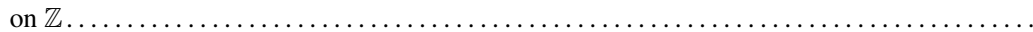

LESSARD, S. Recurrence equations for the probability distribution of sample configurations in exact population genetics models

$1058-1071$

$886-892$

$58-71$

$426-440$

$752-760$

$1191-1194$

$513-525$

$1034-1047$

$1124-1135$

$693-712$

$201-215$

$856-875$

323-334

1023-1033

562-571

732-751 
Letac, G. see BAR-Lev, S. K.

LI, X. AND DING, W. Optimal allocation of active redundancies to $k$-out-of- $n$ systems with heterogeneous components see ZHANG, S.

Lillo, R. E. see RAmíreZ-Cobo, P.

LindBerg, C. see EKSTRÖM, E.

LIU, J. see BLANCHET, J.

LU, B. Recovering a piecewise constant volatility from perpetual put option prices

ŁUCZAK, T. see JANSON, S.

MA, C. AND WANG, L. On estimation of the variances for critical branching processes with immigration

Machado, F. P. see Lebensztayn, E.

Mahmoud, H. M. see Feng, Q. see BALAJI, S.

MAKRI, F. S. On occurrences of $F-S$ strings in linearly and circularly ordered binary sequences ...

MandJes, M. see D'Auria, B.

- see Dह̧BICKI, K.

Marchand, E. see Aoudia, D. A.

MARKströM, K. Correction to Markström (2007, pp. 1119-1121).

608-609

Martinez, M. Z. see Lebensztayn, E.

MARTínez, R. see GonZÁlez, M.

Martínez, S. see Fontbona, J.

Martinucci, B. see Di Crescenzo, A.

Matsui, M. And Mikosch, T. Prediction in a Poisson cluster model $\ldots \ldots \ldots \ldots \ldots \ldots \ldots \ldots$.

MeInERs, M. An almost-sure renewal theorem for branching random walks on the line.........

- see IKSANOV, A.

Mendoza-Pérez, A. F. and Hernández-Lerma, O. Asymptotic normality of discrete-time Markov control processes

Mesfioui, M. see Denuit, M. M.

Mikosch, T. see Matsui, M.

Miyoshi, N. see Ano, K.

MöHLE, M. Looking forwards and backwards in the multi-allelic neutral Cannings population model

Mossel, E. AND SEn, A. Branching process approach for 2 -SAT thresholds . . . . . . . . . . .

Moyal, P. The queue with impatience: construction of the stationary workload under FIFO ......

Nadarajah, S. see Zuoxiang, P.

NaVArro, J. AND SAmaniego, F. J. ANd Balakrishnan, N. The joint signature of coherent systems

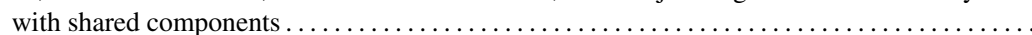

NG, K. W. see CHEN, Y.

- see Konstantinides, D. G.

Norros, I. see JANSON, S.

NuEL, G. On the first $k$ moments of the random count of a pattern in a multistate sequence generated

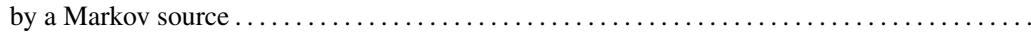

PAKKAnen, M. S. Stochastic integrals and conditional full support $\ldots \ldots \ldots \ldots \ldots \ldots \ldots \ldots \ldots$

PALMOWSKI, Z. AND ZWART, B. On perturbed random walks . . . . . . . . . . . . . . . . see Vlasiou, M.

Papangelou, F. A simple model for random oscillations

$713-731$

$796-810$

$498-512$

$235-253$

Pasurek, T. see Kondratiev, Y.

Perry, D. see Boxma, O.

Piunovskiy, A. B. see Dufour, F.

PollaK, E. Coalescent theory for a monoecious random mating population with a varying size ...

Pollett, P. K. see Barbour, A. D.

Ramírez-Cobo, P., Lillo, R. E. AND Wiper, M. P. Nonidentifiability of the two-state Markovian

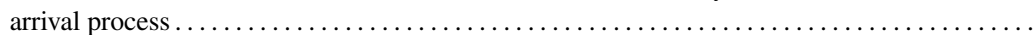

ReINert, G. AND Röllin, A. Random subgraph counts and $U$-statistics: multivariate normal approximation via exchangeable pairs and embedding ...

Riaño, G. see Fralix, B. H. 
Röllin, A. see Reinert, G.

RUZANKIN, P. S. Approximation for expectations of unbounded functions of dependent integer-valued random variables

RYBARCZYK, K. AND STARK, D. Poisson approximation of the number of cliques in random intersection graphs.

Samaniego, F. J. see Navarro, J.

Samorodnitsky, G. see Hult, H.

Savits, T. H. see Block, H. W.

Sen, A. see Mossel, E.

Shaked, M., Sordo, M. A. And SuÁrez-Llorens, A. A class of location-independent variability orders, with applications

$407-425$

Slavtchova-Bojkova, M. see González, M.

Sordo, M. A. see ShaKed, M.

Stadje, W. see Boxma, O.

STARK, D. see RybarczyK, K.

SuÁrez-Llorens, A. see SHaked, M.

Sundaresan, R. see KhandwaWAla, M.

SUZUKI, J. A Markov chain analysis of genetic algorithms: large deviation principle approach ....

TAMAKI, M. Sum the multiplicative odds to one and stop $\ldots \ldots \ldots \ldots \ldots \ldots \ldots \ldots \ldots \ldots \ldots$

TANG, Q. see Konstantinides, D. G.

TAYLOR, P. see FACKRELL, M.

TEHRANCHI, M. R. Characterizing attainable claims: a new proof

$1013-1022$

Tong, Z. see BalaJI, S.

Tortorella, M. On reliability prediction and semi-renewal processes

TYSK, J. see EKSTRÖM, E.

Vlasiou, M. AND PALMOWski, Z. Tail asymptotics for a random sign Lindley recursion....

Voliotis, M. see COHEN, N.

VOLNÝ, D. see ZHAO, O.

Vonta, F. AND Karagrigoriou, A. Generalized measures of divergence in survival analysis and reliability

WANG, J. see BLOCK, H. W.

WANG, L. see MA, C.

WANNTORP, H. see EKSTRÖM, E.

WiPER, M. P. see RAMíreZ-CoBo, P.

Woodroofe, M. see ZHAO, O.

Wu, T.-L. see Fu, J. C.

ZACKs, S. see BoxmA, O.

ZENG, X. A stochastic differential reinsurance game

ZhaNG, H. see FACKRELl, M.

ZHANG, S. AND LI, X. Some new results on the moment generating function order and related life

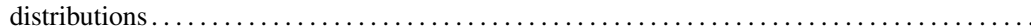

ZHANG, Z. Mixture representations of inactivity times of conditional coherent systems and their

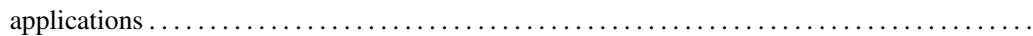

ZhaO, O., WoOdroofe, M. AND VOLNÝ, D. A central limit theorem for reversible processes with

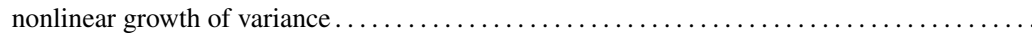

Zuoxiang, P., NADARAJAh, S. AND Fuming, L. Convergence rate of extremes for the general error ZWART, B. see PALMOWSKI, Z. 